\title{
Observing the brain pulsating
}

\author{
Alexandros Andrianakis (iD) - Peter Valentin Tomazic
}

Received: 27 August 2021 / Accepted: 27 October 2021 / Published online: 19 November 2021

(C) The Author(s) 2021

A 75-year-old man presented to the otorhinolaryngology outpatient clinic with a 3-month history of nasal airway obstruction. With anterior rhinoscopy, a livid-colored capillary expansion obstructing the whole nasal cavity was detected. A biopsy specimen was diagnosed as a capillary hemangioma, which was later resected endoscopically in sano. An additional finding of the initial physical examination was a frontal pulsating skin indentation with a central scar (Fig. 1; Video 1, Supplementary material). The patient reported a car accident that occurred 30 years ago as the origin of this indentation. No further information from the patient's history or the medical record was available. Magnetic resonance imaging (MRI) of the face and brain was performed to assess the extent of the nasal hemangioma and, unrelated to the intranasal expansion, an arachnoid cyst below the osseous defect of the left frontal bone was detected with subsequent dilatation of the left lateral ventricle (Fig. 2). The patient's medical history revealed no predisposing diseases or other relevant medical conditions. The diagnosis of a secondary posttraumatic arachnoid cyst was established [1]. On follow-up MRI, this arachnoid cyst without clinical symptoms was stable and remains under surveillance. This is a rare case of a pulsating frontal bone defect due to secondary posttraumatic arachnoid cyst with extension into the lateral ventricle.

Video online The online version of this article contains one video. The article and the video are online available (https://doi.org/10.1007/s00508-021-01980-2). The video can be found in the article back matter as Electronic Supplementary Material.

\section{A. Andrianakis, MD PhD $(\bowtie) \cdot$ P. V. Tomazic}

Department of Otorhinolaryngology, Medical University of Graz, Auenbruggerplatz 26, 8036 Graz, Austria

alexandros.andrianakis@medunigraz.at

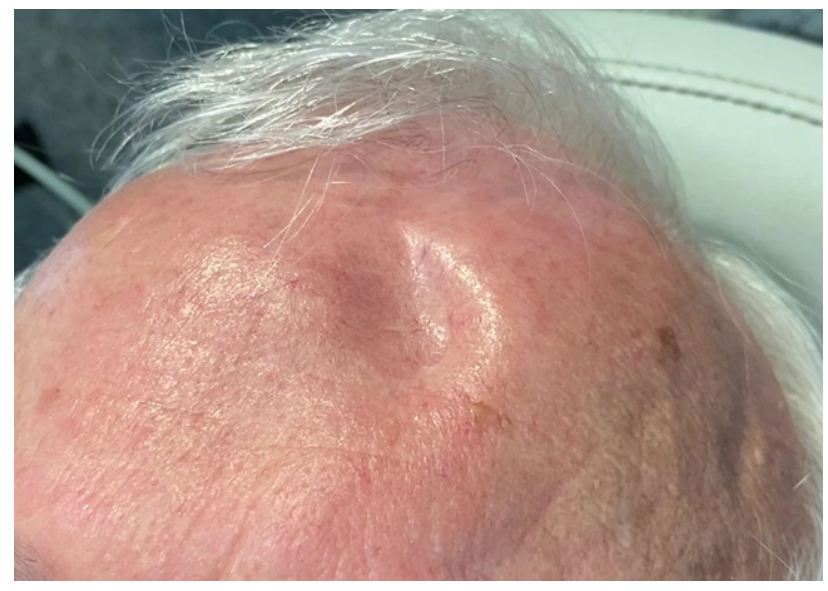

Fig. 1 Frontal pulsating skin indentation with a central scar
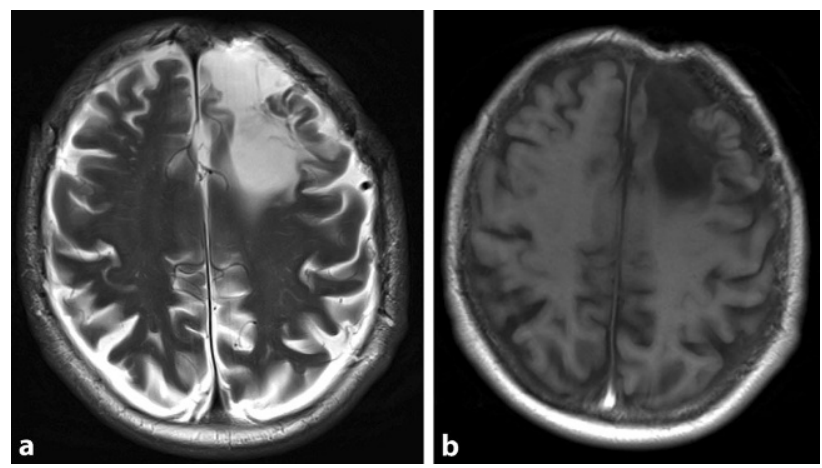

Fig. 2 Secondary posttraumatic arachnoid cyst below the osseous defect of the left frontal bone with subsequent dilatation of the left lateral ventricle on cranial magnetic resonance imaging (a T2-weighted, b T1-weighted) 
Funding Open access funding provided by Medical University of Graz.

\section{Declarations}

Conflict of interest A. Andrianakis and P.V. Tomazic declare that they have no competing interests.

Ethical standards For this article no studies with human participants or animals were performed by any of the authors. All studies performed were in accordance with the ethical standards indicated. All information that could be used to potentially identify the patient was removed. Informed consent for publication was obtained from the patient.

Open Access This article is licensed under a Creative Commons Attribution 4.0 International License, which permits use, sharing, adaptation, distribution and reproduction in any medium or format, as long as you give appropriate credit to the original author(s) and the source, provide a link to the Creative Commons licence, and indicate if changes were made. The images or other third party material in this article are included in the article's Creative Commons licence, unless indicated otherwise in a credit line to the material. If material is not included in the article's Creative Commons licence and your intended use is not permitted by statutory regulation or exceeds the permitted use, you will need to obtain permission directly from the copyright holder. To view a copy of this licence, visit http://creativecommons.org/licenses/by/4.0/.

\section{References}

1. Mustansir F, Bashir S, Darbar A. Management of arachnoid cysts: a comprehensive review. Cureus. 2018;10(4):e2458.

Publisher's Note Springer Nature remains neutral with regard to jurisdictional claims in published maps and institutional affiliations. 